Please do not remove this page

RMIT

UNIVERSITY

\title{
Leading through design: developing skills for affinity and ambiguity
}

Yuille, Jeremy; Varadarajan, Soumitri; Vaughan, Laurene; Brennan, Linda-Marie

https://researchrepository.rmit.edu.au/esploro/outputs/9921862255901341/filesAndLinks?institution=61RMIT_INST\&index=null

Yuille, J., Varadarajan, S., Vaughan, L., \& Brennan, L.-M. (2015). Leading through design: developing skills for affinity and ambiguity. Design Management Journal, 9(1), 113-123. https://doi.org/10.1111/dmj.12009 Document Version: Published Version

Published Version: https://doi.org/10.1111/dmj.12009

Repository homepage: https://researchrepository.rmit.edu.au

(C) 2015 The Design Management Institute

Downloaded On 2023/04/26 12:01:41 +1000

Please do not remove this page 
Thank you for downloading this document from the RMIT Research Repository.

The RMIT Research Repository is an open access database showcasing the research outputs of RMIT University researchers.

RMIT Research Repository: http://researchbank.rmit.edu.au/

\section{Citation:}

Yuille, J, Varadarajan, S, Vaughan, L and Brennan, L 2015, 'Leading through design: developing skills for affinity and ambiguity', Design Management Journal, vol. 9, no. 1, pp. 113-123.

See this record in the RMIT Research Repository at:

https://researchbank.rmit.edu.au/view/rmit:31404

Version: Published Version

Copyright Statement: (c) 2015 The Design Management Institute

Link to Published Version:

http://dx.doi.org/10.1111/dmj.12009

PLEASE DO NOT REMOVE THIS PAGE 


\section{Leading Through Design: Developing Skills for Affinity and Ambiguity}

Jeremy Yuille

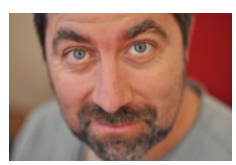

Soumitri Varadarajan

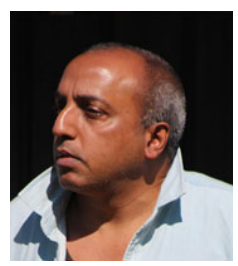

Laurene Vaughan

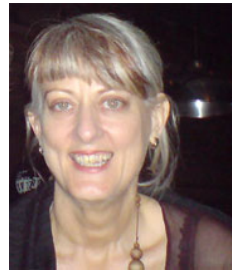

Linda Brennan

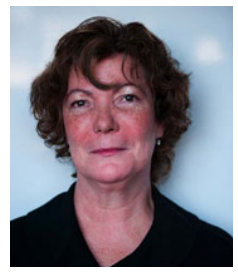

by Jeremy Yuille, Soumitri Varadarajan, Laurene Vaughan, and Linda Brennan Design $\rightarrow \leftarrow$ Business

C or some time now, business discourse has identified that leaders with 1 designerly approaches offer strategic and tactical advantages over those with approaches espoused and taught in traditional MBA and business leadership curricula (Brown, 2009; Liedtka, King, and Bennett, 2011; Liedtka and Mintzberg, 2006; Liedtka and Ogilvie, 2011; Martin, 2009). To clarify designerly, we refer to Cross $(2006,2011)$ and his discussion of an approach to design that privileges discourse around and through making, aesthetic sensitivity, and human-centered perspectives.

In response to this, we have seen an uptake of design discourse and concepts in the traditional leadership curriculum. MBA programs (and business schools more widely) have adopted design as a point of differentiation in a crowded market (e.g., Rottman, Case Western, Oxford, Harvard Business School, Copenhagen Business School etc.). Science, technology, engineering, and mathematics programs have reclaimed design skills and attitudes as a way of crossing silos and addressing ill-framed professional situations (e.g,, Olin, MIT).

Another response for building designerly capacity has been to house design on its own, structurally independent from institutional silos (e+g*, dSchool, HP Institute) or as a separate organizational entity, working in startup/incubator mode (e.g., AC4D, Strelka). Some initiatives by government agencies (e.g*, British Design Council, Singapore Design Council, AIGA Designer of 2015, CIIC Valuing Australia's Creative Industries) approach this issue from a designerly perspective, arguing for the value of awareness, use, and integration of design within traditionally separate industries. Concurrently, more traditional establishments of design education - schools of art and design (e.g., California College of the Arts, School of Visual Arts)- have extended their curricula to explicitly address topics of business, innovation, and leadership. 
The common thread in these developments is the recognition that design and business have different ways of framing knowledge and that each has value to the other. The examples above are tactics for achieving the strategy of bringing design and business together to achieve better outcomes for graduates and the fields these graduates move into. Some principles that tie these designerly leadership tactics together are reflected in the design thinking literature, including a "bias toward action," a particularly tangible take on the literary adage to "show rather than tell' (Brown, 2009) that students of any discipline need to develop their confidence in responding creatively to learning situations (Kelley and Kelley, 2013) and that business will benefit from reviewing the emphasis on knowing to also address the doing and being of leadership (Datar, Garvin, and Cullen, 2010, pp. 7-9).

How might design contribute to this development? To bring us back to the task at hand for this conference thread, we frame this leadership as designerly: a human-centered, aesthetically sensitive, artifact-mediated practice (Cross, 2006, 2011) and now move on to discussing what being designerly might entail.

\section{Being designerly, and the experience turn}

Any useful discussion of designerly leadership requires a holistic interrogation of this role and a subse- quent reframing of it in terms of the disruption that we are gathered here to discuss. The shift from thinking about business and design as a process of ideating and creating things to framing it as ways to support people's experiential needs, wants, and desires is useful here. The turn to experience as a way to frame what it is that products and services do can be seen across business (Christensen et al., 2007; Ulwick, 2005), design education (Davis, 2008), interaction design (McCarthy and Wright, 2004), and wider professional design practice, evidenced by the identification of mental models as a key factor in product design (Norman, 2005, 2013), the rise of fields like user experience design or UX, and much of the design thinking discourse mentioned in the previous section.

In light of this, we propose that people responsible for designerly projects (e.g., designers, managers, teams, networks of stakeholders) are only ever designing to support human experiences: constructed through the lived perception of the people who engage with said projects (Dewey, 1934; Merleau-Ponty, 2002). Designerly leadership begins with this as a grounding principle: that framing what we do in terms of the experiences it supports is as applicable to the design of products and services as it is to the design of projects, organizations, and workplaces. In other words, leadership.

In all these designerly contexts, artifacts are used to mediate shared understandings, across various types of space, with a range of stakeholders, or people. The bias toward showing over telling described earlier is an explicit and deliberate tactic in this experiential turn. We will now explore how this way of working brings a qualitative change in the way teams create meaning. Experience is the key frame, and artifacts are how that frame is enabled, so it is important for us to have a closer look at the way artifacts do what it is we ask of them.

\section{Artifacts as experiences}

The work of John Dewey is closely associated with ways of framing experience in the context of design. Dewey's 1934 book, Art as Experience, was a compulsory text set by Moholy-Nagy at the Institute for Design in Chicago (Findeli, 1990). In particular, the chapter "Having an Experience" formed a cultural backbone to the interaction design program at Carnegie Mellon University (Buchanan, 2011). This adoption of Dewey's ideas by two major design schools, coupled with the strong influence Dewey had on pedagogical thought (Schön, 1992), make Art as Experience a useful place for us to examine how artifacts and experience are connected.

Dewey's (1934) model of experience opens the way for subjective and constructivist approaches to understanding the world. He frames experience as a perceptual act, where the person having the experience 
perceives a relationship between what he or she does, and what that means, or in Dewey's words, "the perception of a relationship between doing and undergoing" (Dewey, 1934, p. 44). Framing experience in this way introduces levels of abstraction between the person having the experience and his or her material reality: to experience, I am perceiving a relationship between something I have done, and what that doing does to me. The doing and undergoing are grounded in actual physical things in the world, but, according to Dewey, the relationship between them is constructed by my perception. Perception is created by the beholder (p. 54).

A constructive perceptual framing of experience is particularly relevant to design management when we begin to discuss artifacts for communicating experience. Again, pragmatist philosophy has some ideas to help us frame this. For Dewey, experience is construction: involving "both action and its result" (1934, p. 82). Concentrating on the result side of this framework, he examines the thingness of expression or how experience manifests in artifacts of human activity: what he refers to as objects. Dewey distinguishes two classes of object: statements-objects that communicate "the conditions under which an experience of an object or situation may be had" (p. 84), and expressions -objects that are an experience. In doing so, Dewey hints at the dif- ferent kinds of agency that artifacts command in a situation, foreshadowing ideas of nonhuman agency at the core of actor network theory (Latour, 2005) and material hermeneutics of Verbeek (2005) that were to emerge much later.

The important aspect of this turn to experience is the explicit move toward incorporating experience as a conceptual model for understanding design situations. Experience-driven approaches have always been an important part of design practice and education. Schön (1984) describes, in a conversation between teacher and pupil, how a designer "anticipates the experienced felt path of a user" (p. 95) as a way to frame reflection in action. This (often) intuitive leap being made by designers results in an appreciation of the experiential perspective held by the people for whom the design is intended. The turn that we refer to, and its implications on the practice of design management in particular, is more deliberate and methodical in the way it approaches human experience.

For example, the social sciences are one place design has turned to for theoretical perspectives on understanding and representing experience (Forlizzi and Battarbee, 2004; Kimbell, 2011). Geertz (1985) uses experience-near and experience-distant concepts as a framework for understanding the difference between accounts of a situation that the inhabitants of that situation might "naturally and effortlessly use to define what he or his fellows see, feel, think, imagine" and accounts of the same situation that communicate what an expert or a specialist might use to "forward their scientific, philosophical, or practical aims" (p. 57). Either approach to experience has its pitfalls, from being drowned in a sea of highly contextual detail, to being divorced from the situation of concern by professional terminology and abstract concepts, but this framework is useful when thinking about communicating experience in design management practice. It also maps quite closely to Dewey's expression/statements dualism.

However, design management differs from anthropology and its relatives because it is concerned with using an understanding drawn from social science methods to inform action. In this sense, it is no surprise that we might find pragmatist ideas at its core. This turn toward experience has changed the kinds of things that design managers pay attention to, and this then changes the way they communicate what it is they see.

\section{Communicating experiences}

As design managers become more interested in how people experience a product or situation, they need ways to identify, communicate, analyze, and evaluate the often intangible concepts that this approach reveals. This shift in focus has resulted in different approaches to the issue of 
communicating experiences. Many approaches are best described as cookbooky (Simon, 1963), presenting how-to examples of design projects as demonstrations of best practice. For example, Dan Brown's (2006) Communicating Design focuses on the creation of deliverables or the graphic and industrial design artifacts that are used to describe different stages and understandings in an interaction design project.

Other authors combine theoretical views of design with practical methods for undertaking design. Bill Buxton (2007) draws on many sources to make a distinction between sketches and prototypes, an approach that resembles Dewey's expressions and statements. Buxton uses this foundation to develop a way of communicating experiences that focuses on the evocative and explorative sketches of design process rather than the didactic or descriptive prototypes associated with design specification.

In a more anthropologically defined example, Indi Young (2008) proposes mental models, a method for analyzing and representing how people conceptually understand a situation that bears close resemblance to the hierarchical model of Operations, Actions, and Activites proposed in Activity Theory by Leont'ev (Koschmann, Kuutti, and Hickman, 1998).

Another arm of design discourse directly addresses the material that designerly leaders work with: Jonas Löwgren and Erik Stolterman (2004, p. 3) suggest that interaction design is an act of shaping a "material without qualities." Richard Buchanan (2011) states that "Interaction design has no material of concern," going on to propose that the primary materials that interaction designers work with are the "purposes and desires of the people we serve."

While experientially driven practices like interaction design use graphic and industrial design to create project and management artifacts, the outcomes of interaction design are not in these artifacts. The outcomes of these practices are seen in the networks of actions that surround these artifacts and the people who undertake these actions. Buchanan's third order of design (1992) draws on the artifacts of second- and first-order design to do its bidding.

Designerly leadership, as we have discussed earlier, is a similar practice, concerned with the connections between the experiences people have in a situation and the things that people make to change that situation. Designerly leaders use artifacts to materialize and surface the intangible, experiential knowledge created during projects. As the materials of designerly leadership become more intangible, design managers use new types of artifacts, in novel ways, to construct, represent, and communicate their understandings of a situation. It makes sense to next explore the way this happens and the capacities that designerly leaders bring to the role.
Bringing this argument back to address being designerly, we want to draw attention to the way designerly and business approaches to the world do not always share similar models of what it means to act in a rational manner. Many business processes seem overly positivist to a designer, while design methods can often be perceived as fluffy or arbitrary (or both) to someone in business. We propose to view design from the perspective of what it is that designers perceive and how they modulate this perception. This shift allows us to move toward the experience of being designerly, by addressing the role of perception in designerly leadership, rather than overlooking it "in favor of the object perceived" (Merleau-Ponty, 2002). We particularly focus on the perception of two complementary qualities: affinity and ambiguity.

\section{Perceiving affinity}

What we do as designers is grounded in how well we can harness our skills at identifying affinity between objects and the systems those objects create. Many design methods explicitly involve some sort of affinity parsing or search for isomorphic relationships between disparate and unfamiliar objects. Card sorting, affinity diagrams, mental models ... these are but a few of the many methods and tools designers use to work out what is going on in a situation, and what to do about it. 
We propose three ways that the perception of affinity is modulated in designerly leadership: affinity spotting, seeking, and making. We describe these three manifestations of affinity ability using a cyclical model, with one leading into the other, and use this cycle to highlight the role that our perception of affinity plays in design processes.

\section{Spotting affinity}

We begin with spotting affinity, because this is the most widely understood manifestation of this ability. Sense-making tasks such as card sorting, mental modeling, or analyzing coded recordings are good examples of affinity spotting. This analytic ability works with a set of collected data, identifying groups of elements that share properties or structure. In many cases, like mental modeling or card sorting, the process of spotting affinity between elements also helps to make sense of the larger set of data by implying categories or taxonomies that help us to understand how to further cluster the elements. It is a process that feeds back on itself, and it is important here to remember that design invokes Herbert Simon's (1963) satisficing to set a breakpoint in this potentially infinite loop (p. 64).

Affinity spotting can be found in the analysis stage of many design projects, as a bridge between researching the situation and changing the situation. To borrow from Simon again, affinity spotting sits between designers using afferent or sensory channels to gather information about a current situation and using efferent or motor channels to move toward a preferred situation (Simon, 1963, pp. 55, 66). Affinity spotting is the most easily understood form of affinity perception, and examples of it can be found in most forms of education.

Humans are, after all, well known for their pattern-matching proclivities.

For this reason, we use spotting as an anchor to help describe two adjacent, and less widely discussed, perceptions of affinity.

\section{Seeking affinity}

Affinity seeking encompasses activities that help to build that set of elements used for spotting. Methods and methodologies including contextual inquiry, ethnography, cultural probes, focus groups, surveys, and even eye tracking are all examples of affinity seeking.

The link between these kinds of research methods and affinity becomes clearer if we look at these activities as the means to gather a better set of data in order to spot affinity rather than goals in themselves. In this way, I am framing evaluation and observation in terms of how they help us ask and answer questions like "how can I identify and solve this problem?" or, more specifically, "what should people do here, and how can we bring that about?" It is interesting to look at how affinity ability can help us be better at researching a design situation.
Many methods that we clump under affinity seeking talk about the need for designers to distance themselves from the situation, to "leave your assumptions at the door" (Young, 2008, p. 150) to objectively perceive elements in the situation (e.g., behaviors, objects, beliefs, actors) without subjective biases.

Many methods have been designed to help us fake objectivity and build a data set that satisfices requirements for variety, so we can then apply our natural pattern-recognition ability in the spotting phase. We might look at this faking of objectivity as a suspension of the affinity-spotting activity: turning that part of our perception off, so we do not bias the outcomes with our previous experiences. Of course, this is impossible and it might make more sense to think of this process as a suspension of affinity, somewhat akin to the suspension of disbelief we encounter with the movies or fiction. It is also worth remembering that not applying something does not necessarily imply its absence.

Affinity ability is required to suspend affinity spotting, and therefore we suggest that designers can become better at seeking affinity by developing a more sophisticated understanding and control over how they modulate their perceptions of affinity. Some great examples of seeking affinity are the many permutations that research methods undergo when they are applied in design practice. For example, 
consider guerrilla or quick and dirty versions of anthropological methods like rapid ethnography (Millen, 2000; Norman, 1999).

\section{Making affinity}

The activities previously described help design managers and teams understand the world, but at some stage designerly leaders need to put something back into that world, to make changes. This process of creating things that solve problems can be framed as making affinity with a perceived gap that exists in the design situation. It is important to note that many people think this is all that design does, because it is the only part of design that most people experience. For this reason, it is not surprising that this is the part of design most students sign up for.

Making affinity is one way to describe what is happening when designers respond to the "job to be done" (Christensen et al,, 2007; Ulwick, 2005) of an ill-framed design situation. It is demonstrated by descriptions of intuitive interfaces (affinity with what we know already) or innovative services (affinity with perceived opportunities and latent mental models). This is where Kolko's (2011) magic happens, and it is from here that our theory of designerly leadership builds.

When designerly leaders use artifacts in the service of a project, they make affinity with the problems they have framed. The cyclical/iter- ative nature of these affinity perceptions becomes apparent if we view the framing process as one of making affinity with the "problem of the problem" (Schön, 1984) or the gap that the design problem has not yet been usefully defined. We can see that affinity perception occurs at different scales and stages of a designerly process when we seek, spot, and make affinity with different elements of the situation.

Framing the designerly use of artifacts as a perceptual act lets us move to discussing the choices presented when a designer, design manager, or designerly leader puts something into the design situation. In this act, they affect the situation and the perceptions of everyone involved. We propose this act can be conceptualized as a craft and that designerly leaders may develop their capacity to successfully lead in the same way they develop capacity in any craft, through deliberate practice, informed by a sensitivity to how the things they put into the world engage other people (e.g., coworkers, stakeholders, partners, clients, users) to move a project forward. In order to examine this aspect of leadership, we now turn to a perceptual complement of affinity: how we perceive things to be different or unconnected, namely, ambiguity.

\section{Using ambiguity}

In this section, we lay out strategic approaches to using ambiguity as part of a designerly practice. We identify these approaches as pragmatic, critical, and enterprising. We begin with the pragmatic, an attitude that resonates with the widely held perception that the purpose of design is to solve problems.

\section{Pragmatic}

A pragmatic approach to designerly leadership seeks to reduce and excise ambiguity. Leaders and designers who use this approach aim to minimize the effects of cognitive load and reduce conceptual friction or dissonance in order to design things that are intuitive and usable.

We use the term pragmatic for two reasons: first, this approach to design is ultimately interested in fitting a design to its intended use and users. There is a pragmatism associated with this approach that acknowledges design has a job to do, and that job is best accomplished by designing things to be as unambiguous as possible. This approach is related to a modernist aesthetic of rational simplicity and the removal of complexity. Its agenda is the excision of ambiguity, often through understanding the user.

Second, theorists and practitioners of this approach often refer (as we have) to pragmatism for models of experience and perception. Design literature that describes this approach has a strong scientific background using models derived from perceptual psychology and cognitive science (Buchanan, 1992; 
Cooper, 1995; McCarthy and

Wright, 2004; Norman, 2013).

The kind of artifacts and actions often used to reduce ambiguity include explanatory and specification documents, mental models (Young, 2008), wireframes, strategic plans, prioritization exercises, and affinity mapping.

\section{Critical}

Conversely, a critical use of ambiguity seeks to use or exercise ambiguity in a project, often to draw attention to the relationship between an artifact and its context. This approach reframes design as an agent of critical reflection, where artifacts are intentionally designed to be ambiguous, in order to encourage people to interpret the artifact and situation for themselves (Gaver, Beaver, and Benford, 2003). The reframe or using a design to redefine its own boundaries of agency is one core design move of a critical approach.

We take the name critical from Dunne and Raby's (2001) Design Noir, in which they propose critical design as a strategy of using design to “... stimulate discussion and debate amongst designers, industry and the public ..." (p. 58). A critical approach to ambiguity aims to make questions where none were perceived before, either to critique the situation or lead to a deeper conceptual appropriation (Gaver et al., 2003) of a designed artifact. It is where we problematize the situation and invite our colleagues to be part of it.
We see critical uses of ambiguity in artifacts and actions including exhibitions (Dunne and Raby, 2001), cultural probes (Gaver, Dunne, and Pacenti, 1999), bodystorming (Oulasvirta, Kurvinen, and Kankainen, 2003), and other forms of experience prototyping (Buchenau and Suri, 2000).

\section{Enterprising}

A third approach uses the second to achieve the first. An enterprising approach to ambiguity employs the ambiguous to scaffold mutual engagement in a shared goal. It uses ambiguity as an invitation to negotiate and construct meaning between different stakeholders in a design project. Here, the term enterprising refers to Wenger's (1998) concepts of shared enterprise, mutual engagement, and the duality of participation and reification.

We have deliberately avoided using a term like participatory because of the disparate and potentially confusing connotations of this term. We are not referring to Participatory Design, as the field of research and practice is called, although many of these ideas may have application in that field.

We propose that these three ways of using ambiguity in design are useful for thinking about what it is that designerly leaders do: persistently flipping back and forth between exercising ambiguity to open up a discourse and excising ambiguity in order to decide on the next course of action.
As the model of rationality shifts throughout a project, the designerly leader modulates his or her perception of affinity to respond to these shifts. Artifacts that open up discourse at one stage of a project will close it down in another, and vice versa. The challenge for designerly leaders is to not only master the skills of understanding, representing, and influencing what is happening in a project or an organization, but also to adapt their actions to make affinity with the current model of rationality their team is inhabiting.

\section{Designerly pedagogy}

So. How can we teach this? Or, more accurately, how might we create experiences that help to build these capacities in our graduates? Following is a set of provocations intended to develop discourse and hopefully influence actions in design, business, and leadership programs.

We believe that programs wanting to educate design managers for strategic roles should...

\section{Learn (more) about learning}

It is all well and good for us to say, "we should teach our students how to perceive affinity and perform ambiguity," but before we begin writing courses like Affinity Perception 101 or Introduction to Ambiguity, it is important to note that the worlds of business and design are not the only ones disrupted by the experience turn described above. Education, or to 
frame it more experientially, learning, is in the throes of several paradigm shifts that are relevant to our topic.

To begin, there is the neuro turn, or looking at how our understanding of the brain (arguably the physical material of cognition) might impact what we do to encourage different forms of cognition (learning). Most interesting here are theories of neuroplasticity, commonly understood in terms such as fire and wire or that the brain continually changes throughout our lifetime and that learning is a physical process of repeatedly stimulating a network of neurons. These theories, pioneered by Hebb (1949), have been recently popularized in more widely received works by Doige (2007) and Coyle (2009). Works of note with specific relevance to education include Dweck's (2006) discussion of how growth versus fixed mindset plays a key role in academic (and extended) performance, and Perkins's (1995) discussion of ways that intelligence may be framed as learnable, leading to his theory of dispositions (Perkins, Tishman, Ritchhart, Donis, and Andrade, 2000). Perkins's (2010) formulation of authentic learning experiences as "playing the whole game" resonates with much of what Datar et al. (2010) list as unmet needs of MBA programs, particularly the reliance of traditional education toward elementitis, putting off holistic integrated experiences of practice because teaching the separate elements in isolation is more efficient, and abou- titis, teaching about something instead of teaching to do the thing itself.

These and many other works repeatedly discuss the importance of changing the way we teach and assess (Bohemia and Davison, 2012) to not only support the way we actually seem to learn, but also to develop new forms of intelligence that contemporary society deems useful. However, design and business programs persist with antiquated models of learning. Lectures, tutorials, classrooms, briefs, exams, portfolios, rooms that reset to zero each teaching period-all these forms privilege 19th-century models of knowledge that is transmitted or, if we are being generous, 20th-century theories of skills that are evident in things produced. These modes of intellectual (dis)engagement make it very difficult for educators to evaluate the perceptual capacities of our students, let alone allowing the students to experience what it is like to do or be the practitioner they aspire to.

In short, if we want to change the kind of graduates our schools produce, we need to change the way these schools produce graduates.

\section{Drill, train, and coach for perceptual sensitivity}

Drilling, training, and coaching are not new to business, leadership, or even design programs. This is great because the organizational infrastructure and practices are already there. We propose a slight tweak in the way these activities occur: a shift to explicitly addressing the perception as opposed to "that which is perceived” (Merleau-Ponty, 2002).

To drill students seems antiquated and at odds with the statements above. Surely we should all just get dedicated studios with ideapaint walls and movable furniture and throw students in the deep end of doing designerly leadership? Possibly, as Barry and Meisiek (2014) show, the jury is still out on studios.

The path to graduate programs is narrow and stressful. Moves toward standardized testing across OECD education systems means that, by the time our prospective designerly leaders reach us, many of them are already broken - broken to the increasingly competitive and objectivist testing regime current secondary and tertiary systems put them through. Some small changes are afoot (see previous section), but there remains the other key challenge to 21 st-century education: that to get ourselves out of the pickle we have designed ourselves into, we need to develop designerly leadership capabilities in all types of people, not just the ones who already "get it."

\section{Develop rhetorical capacity}

Our final point is directed equally toward design and business programs: designerly leaders should have a sophisticated knowledge of, and ability with, the rhetorical agency of artifacts and actions. Graduates should know how to do things with things and words (after Austin, 1962). 
We are not just talking about convincing clients or stakeholders to agree with our decisions on what color their logo needs to be, although that could be a good place to start. We also refer to how designerly leaders can develop conviction in the people they work with. How can a leader convince a team to stop trying to solve things and start trying to see things and help their teams and stakeholders to reframe issues and extend designerly capacity throughout organizations?

Rhetoric, and its Aristotelian triangle of logos, ethos, and pathos, is a useful rubric to help us see where curricula can be tweaked. For instance, design students wanting to act in strategic roles might need to develop their logos (no Logos?) or methods for appealing to logical rationality. These include not only methods of analysis but also capacity in perceiving what rational actually means in the design situation. Business students wanting to act in strategic roles might need to develop their pathos or ability to appeal to emotions and affect. This includes not only methods of synthesis, but also the expertise with affinity and ambiguity we described above.

\section{Conclusion}

In this paper, we have focused on the designerly act of making affinity with a perceived gap in the design situation and subsequent choice to dial the ambiguity of the situation up or down to drive a project forward. We have not yet explored what this implies, that there are ways that designerly leaders can put things into the world and affect the perceived ambiguity of a situation or that artifacts have performative potential.

We propose that any programs wanting to educate design managers for strategic roles should consider expanding their pedagogical palette; explicitly attending to perception in the syllabus; and developing appreciation of, and skills with, the rhetorical agency of artifacts and actions.

$$
\text { Reprint \#15091YUI113 }
$$

\section{References}

Austin, J. L. (1962). How to Do Things with Words. Oxford, UK: Oxford University Press.

Barry, D., Meisiek, S. (2014). "Discovering the Business Studio." Journal of Management Education. doi:10.1177/ 1052562914532801

Bohemia, E., Davison, G. (2012). "Authentic Learning: The Gift Project." Design and Technology Education: An International Journal, 17(2).

Retrieved from http://ojs.lboro.ac.uk/ ojs/index.php/DATE/article/view/ 1731

Brown, D. (2006). Communicating Design: Developing Web Site Documentation for Design and Planning (1st ed.). San Francisco: New Riders Press.

Brown, T., Katz, B. (2009). Change by Design: How Design Thinking Transforms Organizations and Inspires Innovation. New York: Harper Business.

Buchanan, R. (1992). "Wicked Problems in Design Thinking." Design Issues, 8(2), pp. 5-21.
Buchanan, R. (2001). "Design Research and the New Learning." Design Issues, 17(4), pp. 3-23.

Buchanan, R. (2011, February). "Interaction Design: What Are We? Where Are We? Where Are We Going?" Keynote conference presentation presented at the Interaction 11, Boulder. Retrieved from http:// www.ixda.org/resources/richardbuchanan-keynote

Buchenau, M., Suri, J. F. (2000). "Experience Prototyping." In Proceedings of the 3rd Conference on Designing Interactive Systems: Processes, Practices, Methods, and Techniques (pp. 424 433). New York: ACM Press.

Buxton, B. (2007). Sketching User Experiences: Getting the Design Right and the Right Design (1st ed). San Francisco: Morgan Kaufmann.

Christensen, C. M., Anthony, S. D., Berstell, G., Nitterhouse, D. (2007). "Finding the Right Job for Your Product." MIT Sloan Management Review, 48(3), pp. 38-47.

Cooper, A. (1995). About Face: The Essentials of User Interface Design. New York: John Wiley \& Sons. Coyle, D. (2009). The Talent Code: Greatness Isn't Born. It's Grown. Here's How (1st ed.). New York: Bantam. Cross, N. (2006). Designerly Ways of Knowing (1st ed.). New York: Springer.

Cross, N. (2011). Design Thinking: Understanding How Designers Think and Work. Oxford, UK: Bloomsbury Academic.

Datar, S., Garvin, D. A., Cullen, P. G. (2010). Rethinking the MBA: Business Education at a Crossroads (1st ed.). Boston: Harvard Business Review Press. 
Davis, M. (2008). “Toto, I've Got a Feeling We're Not in Kansas Anymore ...."Interactions, 15(5), pp. 28-34.

Dewey, J. (1934). Art as Experience. New York: Minton, Balch \& Co.

Doidge, N. (2007). The Brain That Changes Itself: Stories of Personal Triumph from the Frontiers of Brain Science (reprint ed.). New York: Penguin Books.

Dunne, A., Raby, F. (2001). Design Noir: The Secret Life of Electronic Objects. Basel, Switzerland: Birkhäuser.

Dweck, C. S. (2006). Mindset: The New Psychology of Success. New York: Random House.

Findeli, A. (1990). "Moholy-Nagy's Design Pedagogy in Chicago (193746).” Design Issues, 7(1), pp. 4-19.

Forlizzi, J., Battarbee, K. (2004). "Understanding Experience in Interactive Systems." In Proceedings of the 5th Conference on Designing Interactive Systems: Processes, Practices, Methods, and Techniques (pp. 261-268).

Gaver, W. W., Beaver, J., Benford, S. (2003). "Ambiguity as a Resource for Design." Proceedings of the SIGCHI Conference on Human Factors in Computing Systems (pp. 233-240). Fort Lauderdale, FL: ACM Press.

Gaver, B., Dunne, T., Pacenti, E. (1999). “Design: Cultural Probes." Interactions, 6(1), pp. 21-29.

Geertz, C. (1985). Local Knowledge: Further Essays in Interpretive Anthropology (3rd ed.). New York: Basic Books.

Hebb, D. O. (1949). The Organization of Behavior: A Neuropsychological Theory. Hillsdale, NJ: Erlbaum.

Kelley, T., Kelley, D. (2013). Creative Confidence: Unleashing the Creative
Potential Within Us All. New York: Crown Business.

Kimbell, L. (2011). "Rethinking Design Thinking: Part I." Design and Culture, 3(3), pp. 285-306.

Kolko, J. (2011). Exposing the Magic of Design: A Practitioner's Guide to the Methods and Theory of Synthesis (1st ed.). Oxford, UK: Oxford University Press.

Koschmann, T., Kuutti, K., Hickman, L. (1998). "The Concept of Breakdown in Heidegger, Leont'ev, and Dewey and Its Implications for Education." Mind, Culture, and Activity, 5, pp. 25-41.

Latour, B. (2005). Reassembling the Social: An Introduction to Actor-Network-Theory. Oxford, UK: Oxford University Press.

Liedtka, J., Mintzberg, H. (2006). “Time for Design." Design Management Review, 17, pp. 10-20.

Liedtka, J., Ogilvie, T. (2011). Designing for Growth: A Design Thinking Tool Kit for Managers (1st ed.). New York: Columbia University Press.

Lowgren, J., Stolterman, E. (2004). Thoughtful Interaction Design: A Design Perspective on Information Technology. Cambridge, MA: MIT Press. Retrieved from http://porta1.acm.org/citation.cfm?id $=1050958 \&$ $\mathrm{dl}=\mathrm{ACM} \&$ coll $=$ Portal $\&$ CFID $=$ 81554788\&CFTOKEN =549 23344

Martin, R. L. (2009). The Design of Business: Why Design Thinking Is the Next Competitive Advantage (3rd ed.). Boston: Harvard Business Review Press.

McCarthy, J., Wright, P. (2004). Technology as Experience. Cambridge, MA: MIT Press.
Merleau-Ponty, M. (2002). Phenomenology of Perception (2nd ed.). London: Routledge.

Millen, D. R. (2000). Rapid Ethnography: Time Deepening Strategies for HCI Field Research. New York: ACM Press.

Norman, D. (1999). "Rapid Ethnography." In H. Aldsersey-Williams, J. Bound, R. Coleman (Eds.), Methods Lab: User Research for Design. London: Helen Hamlyn Research Centre, Royal College of Art. Retrieved from http://www.education.edean.org/ pdf/Tool039.pdf

Norman, D. (2005). Emotional Design: Why We Love (or Hate) Everyday Things (1st ed.). New York: Basic Books.

Norman, D. (2013). The Design of Everyday Things (revised and expanded ed.). New York: Basic Books.

Oulasvirta, A., Kurvinen, E., Kankainen, T. (2003). "Understanding Contexts by Being There: Case Studies in Bodystorming." Personal and Ubiquitous Computing, 7(2), pp. 125-134.

Perkins, D. (1995). Outsmarting IQ: The Emerging Science of Learnable Intelligence. New York: Simon and Schuster.

Perkins, D. (2010). Making Learning Whole: How Seven Principles of Teaching Can Transform Education (1st ed.). San Francisco: JosseyBass.

Perkins, D., Tishman, S., Ritchhart, R., Donis, K., Andrade, A. (2000). "Intelligence in the Wild: A Dispositional View of Intellectual Traits." Educational Psychology Review, 12(3), pp. 269-293. 
Schön, D. A. (1984). The Reflective Practitioner: How Professionals Think in Action (1st ed.). New York: Basic Books.

Schön, D. A. (1992). "The Theory of Inquiry: Dewey's Legacy to Education." Curriculum Inquiry, 22(2), pp. 119-139.

Simon, H. A. (1963). The Sciences of the Artificial (3rd ed.). Cambridge, MA: MIT Press.

Ulwick, A. (2005). What Customers Want: Using Outcome-Driven Innovation to Create Breakthrough Products and Services (1st ed.). New York: McGraw-Hill.

Verbeek, P.-P. (2005). What Things Do: Philosophical Reflections on Technology, Agency, and Design. University Park, PA: Penn State University Press.

Wenger, E. (1998). Communities of Practice: Learning, Meaning, and Identity. New York: Cambridge University Press.

Young, I. (2008). Mental Models: Aligning Design Strategy with Human Behavior (1st ed.). Brooklyn, NY: Rosenfeld Media.

\section{Author biographies}

Jeremy Yuille is a designer, an educator, and an exuberant learner. While he loves designed objects, he is more interested in framing design as a practice that creates value and connects disciplines. His work spans strategic design for civic engagement and participatory democracy, digital presentation platforms, and baking creativity into education. He is a director emeritus of the IxDA and leads the Master of Design Futures program at RMIT University.

Soumitri Varadarajan is a deputy dean of Industrial and Interior Design at RMIT University (Melbourne, Australia). He has worked at Hitachi in Japan and directed studios in Israel, India, Netherlands, China, Turkey, Portugal, and France. He is currently working on the Encyclopedia of Asian Design as an editor focusing on South and Southeast Asia. With a first degree in mechanical engineering and $\mathrm{PhD}$ in social science to add to his industrial design training, he brings to his design thinking a combination of perspectives from engineering, material culture, and systems thinking. His work in design for environment has been in teaching ecoredesign within the context of design for mass manufacture, prototyping green service solutionswaste and pedal power - and in setting up ecodesign capacity in Portugal and India. He has run a small/ medium-sized enterprise (SME) focused on fabrication and metal furniture production in India. He has run executive training sessions for senior management from China and
India. He has done training programs for staff in SMEs focused on improving capacity in environmental and sustainable product management.

Laurene Vaughan is a deputy dean of Design, Games, and Interaction in the School of Media and Communication, RMIT University, and a research leader within the RMIT Design Research Institute. She was invited to the position of Neirenberg Chair, Distinguished Professor of Design, at Carnegie Mellon University, 2012-2013. Between 2005 and 2010, she was project leader and researcher within the Australasian CRC for Interaction Design. As a practicing artist, designer, writer, and educator, her research explores the interactive and situated nature of human experience.

Linda Brennan is the Inaugural Professor of Advertising at RMIT and is based in the School of Media and Communication at RMIT University in Melbourne. In the lead-up to becoming a full-time academic, she had an active consulting practice in marketing and strategic research. Her research interests are social and government marketing and especially the influence of marketing communications and advertising on behavior. 